\title{
Review Article \\ Gender Differences in Birdshot Chorioretinopathy and the White Dot Syndromes: Do They Exist?
}

\author{
Lisa J. Faia ${ }^{1,2}$ \\ ${ }^{1}$ Department of Ophthalmology, Oakland University William Beaumont School of Medicine, Rochester, MI 48309, USA \\ ${ }^{2}$ Retina and Uveitis, Associated Retinal Consultants, P.C., Royal Oak, MI 48073, USA \\ Correspondence should be addressed to Lisa J. Faia; lfaia@arcpc.net
}

Received 1 October 2013; Revised 19 December 2013; Accepted 21 December 2013; Published 9 February 2014

Academic Editor: Debra Goldstein

Copyright (C) 2014 Lisa J. Faia. This is an open access article distributed under the Creative Commons Attribution License, which permits unrestricted use, distribution, and reproduction in any medium, provided the original work is properly cited.

\begin{abstract}
Inflammatory conditions that affect the posterior pole are diverse. Specifically, birdshot chorioretinopathy and the white dot syndromes present with multiple white dots in the fundus. These diseases appear to affect similar age groups but there is question as to whether or not a difference exists between the genders. This review summarizes the current studies on birdshot chorioretinopathy and the white dot syndromes as they are related to gender, exploring the differences, if any, which may exist between prevalence, clinical presentation, and treatment response for these diseases. Though the specific etiology of these diseases remains unclear, future treatments may be guided as to how these diseases affect the sexes differently.
\end{abstract}

\section{Introduction}

The spectrum of posterior uveitis disorders is broad. There is a specific group, called the white dot syndromes, which presents with multiple white dots in the fundus. The characteristic inflammatory changes of the choroid and retina are typically yellow-white foci beneath or in the deep retina and include birdshot chorioretinopathy (BCR), acute posterior multifocal placoid pigment epitheliopathy (APMPPE), multiple evanescent white dot syndrome (MEWDS), multifocal choroiditis with panuveitis (MFC), punctate inner choroidopathy (PIC), and acute zonal occult outer retinopathy (AZOOR). These disorders represent a range of presentations, including that of demographics, age, genetic, and gender prevalence. The etiology of these diseases is not completely understood nor is the best approach for treatment of these diseases. The purpose of this review was to assess the current scientific evidence as it is related to the possible gender differences that may exist in birdshot chorioretinopathy and the white dot syndromes.

\section{Methods and Materials}

A systematic review of all the peer-reviewed, English language articles indexed in PubMed about BCR, APMPPE,
MEWDS, MFC, PIC, and AZOOR was carried out. For each disease, specific terms were used and reported. Studies with ten or more patients in which patient data included gender and age were reviewed and summarized. Articles were also reviewed for any mention of presentation differences between the sexes and, for those that specified treatment, reviewed to see if differences were noted in the treatment response.

\section{Results and Discussion}

3.1. BCR. Birdshot chorioretinopathy (BCR) is a rare, chronic, bilateral, posterior inflammatory disease involving the retina and the choroid. The earliest report of this disorder was in 1949 by Franceschaetti and Babel as candle wax spot chorioretinopathy ("la choriorétinite en täche de bougie") [1]. Ryan and Maumenee coined the term "birdshot retinochoroidopathy" to describe the distinctive lesions seen in the fundus, characterized by multiple, small, white spots that had the appearance of the scatter from a shotgun (Figure 1) [2].

$\mathrm{BCR}$ is relatively uncommon, ranging from 1.2 to $7.9 \%$ of patients with posterior uveitis $[3,4]$. It mostly affects those of Northern European ancestry and those of middle age (average age 48-53), though the range has been reported between 15 and 79 years old $[5,6]$. In Shah et al. review, one of 


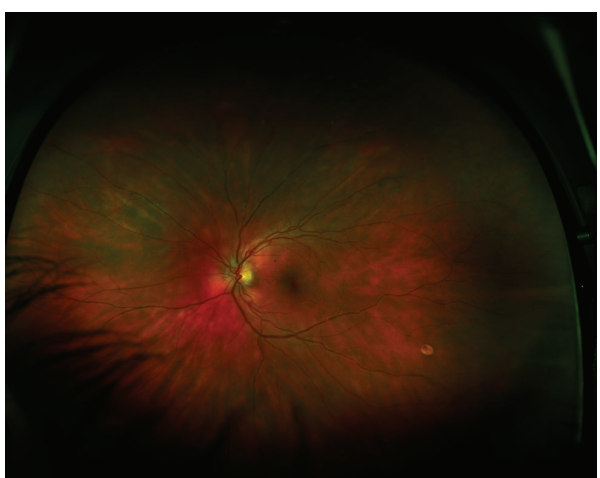

(a)

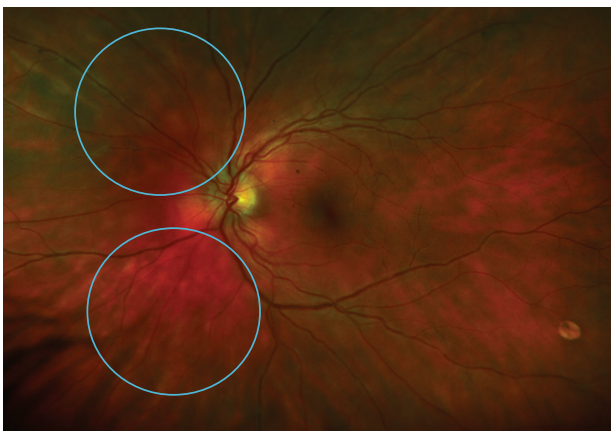

(c)

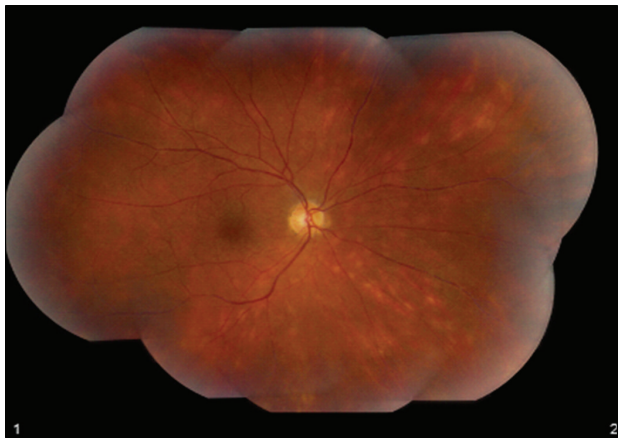

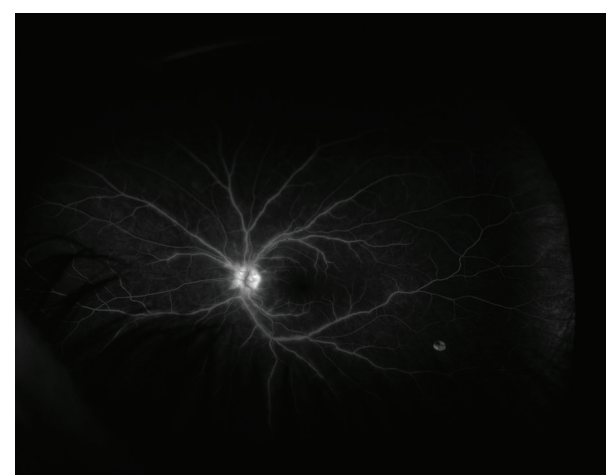

(b)

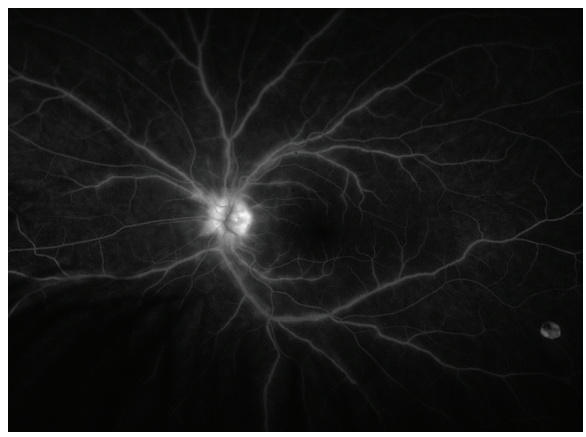

(d)

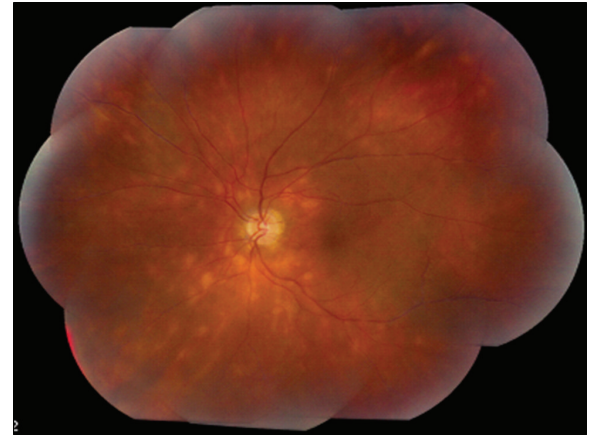

(e)

FIGURE 1: (a) Wide-field fundus photograph of a 34-year-old Caucasian male (diagnosed with BCR one year prior to presentation) with (b) corresponding fluorescein angiogram demonstrating vasculitis. (c) Magnified view of the classic lesions (blue circles) and (d) magnified view of vasculitis and late optic disc leakage. No prior treatment. (e) In contrast, bilateral fundus photography of a 55-year-old Caucasian woman diagnosed with BCR two years prior to presentation with more impressive lesions and vascular sheathing. No prior treatment.

the largest reviews on birdshot chorioretinopathy, there was slight female predominance $(54.1 \%)$, though there have been other studies that have shown a near equal male : female ratio and some with slight male predominance [6-10].

In evaluating the current literature for BCR, data was obtained from 16 articles (Table 1) [6, 8, 9, 11-23]. In PubMed, the term "birdshot chorioretinopathy," using all or parts of the term, brought up 112 articles. After reviewing and eliminating reports with less than 10 patients, no specificity on patient data for gender and age, and those in which data was repeated, 16 reports remained. Eleven of the 16 reports revealed female predominance, ranging from 54.1 to $100 \%$. When all patients from these articles were considered $(n=1157), 669$ patients $(58 \%)$ were female. The mean age was 53.3 years old, with a range from 46.5 to 61 years old.

3.2. APMPPE. APMPPE was first described by Gass in 1968 as a syndrome of multiple, large, placoid lesions at the level of the retinal pigment epithelium that are associated with temporary vision loss [24]. It affects both men and women without preference, usually of good health between the ages of 20 and 50 years old [25]. Vision loss is usually bilateral but may be asymmetric. APMPPE is characterized by bilateral, multifocal yellowish-white placoid lesions usually less than 
TABLE 1: Reports for birdshot chorioretinopathy.

\begin{tabular}{|c|c|c|c|c|}
\hline Author & Year published & No. of patients & No. of women (\%) & Average age (years) \\
\hline Keane et al. [11] & 2013 & 12 & $5(42)$ & 59 \\
\hline Yang and Foster [12] & 2013 & 17 & $8(47)$ & 52 \\
\hline Cervantes-Castaneda et al. [23] & 2013 & 49 & $28(57)$ & 48.8 \\
\hline Papadia and Herbort [13] & 2013 & 25 & $19(76)$ & 49.6 \\
\hline Artornsombudh et al. [22] & 2013 & 22 & $17(77.3)$ & 53 \\
\hline Kuiper et al. [14] & 2011 & 16 & $15(94)$ & 61 \\
\hline Rothova et al. [21] & 2011 & 76 & $49(64)$ & 54 \\
\hline Giuliari et al. [15] & 2010 & 15 & $15(100)$ & 52.3 \\
\hline Pagnoux et al. [16] & 2010 & 118 & $73(62)$ & 51.5 \\
\hline Trinh et al. [17] & 2009 & 10 & $4(40)$ & 46.5 \\
\hline Kappel et al. [18] & 2009 & 63 & $38(60)$ & 60.9 \\
\hline Thorne et al. [9] & 2008 & 55 & $25(45)$ & 56 \\
\hline Monnet et al. [19] & 2006 & 80 & $51(64)$ & 55.6 \\
\hline Shah et al. [6] & 2005 & 522 & $283(54.1)$ & 53 \\
\hline Sobrin et al. [20] & 2005 & 23 & $13(56.5)$ & 49 \\
\hline Rothova et al. [8] & 2004 & 54 & $26(48)$ & 53 \\
\hline
\end{tabular}

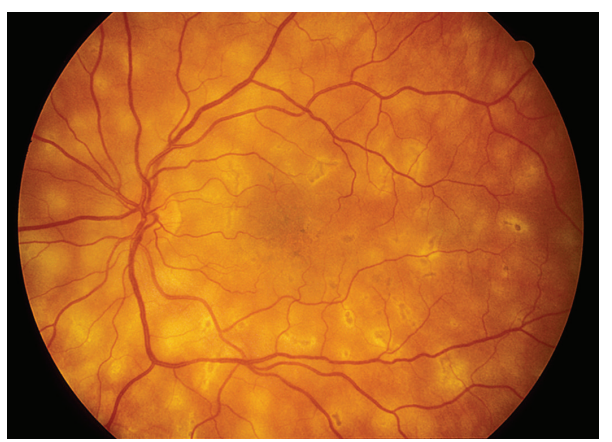

(a)

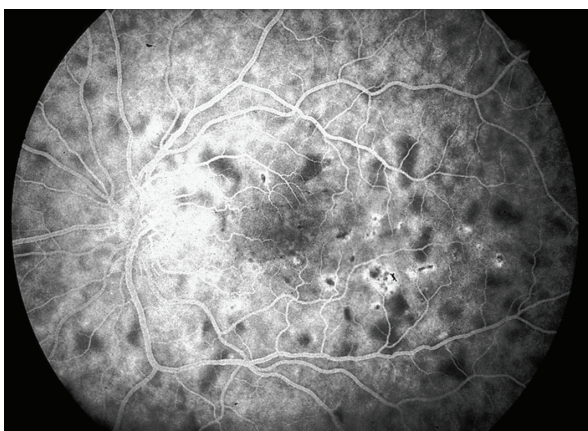

(b)

Figure 2: (a) Fundus photograph and corresponding (b) midphase fluorescein angiogram showing blockage of some lesions and the beginning of staining of other lesions as the later phase begins in APMPPE.

1 disc diameter in size found in the posterior pole. Classically, these lesions, on fluorescein angiogram, "block early, stain late (Figure 2)." The lesions fade over 1-2 weeks, usually without significant sequelae. Though the etiology is not well understood, it has been postulated that a possible viral agent may be the inciting factor, as patients report a preceding viral prodrome.

In evaluating the current literature for APMPPE, data was obtained from 3 articles (Table 2) [26-28]. In PubMed, the term "acute posterior multifocal placoid pigment epitheliopathy," using all or parts of the term, brought up 205 articles. After reviewing and eliminating reports with less than 10 patients, no specificity on patient data for gender and age, and those in which data was repeated, 3 reports remained. None of the reports revealed female predominance, ranging from 45.5 to $50 \%$. When all patients from these articles were considered $(n=405), 185$ patients $(46 \%)$ were female. The mean of the average age was 27.1 years old, with a range from 26.2 to 28.6 years old.
3.3. MEWDS. MEWDS, first described by Jampol et al., presents with numerous small, discrete white lesions in the deep retina or level of the RPE and appears in the posterior pole and extends to the midperiphery [29]. Classically, the fluorescein demonstrates wreath-like lesions and granular appearance to the fovea (Figure 3 ). Though usually unilateral in young, myopic women ages 20 to 45 years old, there have been bilateral cases described [30]. A preceding viral illness has been reported in approximately $1 / 3$ of cases, and though the cause is unknown, a viral etiology has been suggested. This disease usually resolves spontaneously.

In evaluating the current literature for MEWDS, data was obtained from 3 articles (Table 3) [13, 31, 32]. In PubMed, the term "multifocal evanescent white dot syndrome," using all or parts of the term, brought up 151 articles. After reviewing and eliminating reports with less than 10 patients, no specificity on patient data for gender and age, and those in which data was repeated, 3 reports remained. Two of the three reports revealed female predominance, ranging from 50 to $91 \%$. 
TABLE 2: Reports for acute posterior multifocal placoid pigment epitheliopathy.

\begin{tabular}{lcccc}
\hline Author & Year published & No. of patients & No. of women (\%) & average Age (years) \\
\hline Thomas et al. [26] & 2012 & 18 & $9(50)$ & 28.6 \\
Fiore et al. [27] & 2009 & 187 & $85(45.5)$ & 26.2 \\
Jones [28] & 1995 & 200 & $91(45.5)$ & 26.5 \\
\hline
\end{tabular}

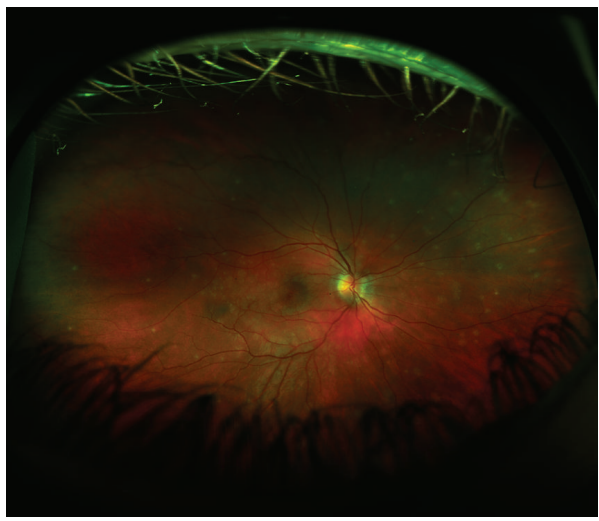

(a)

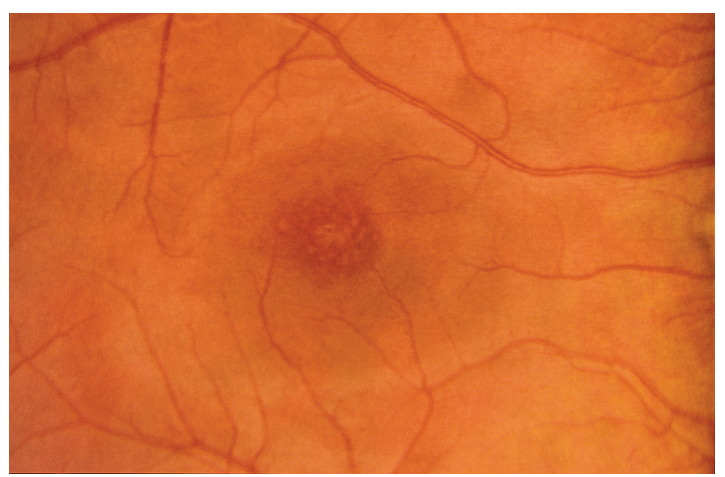

(c)

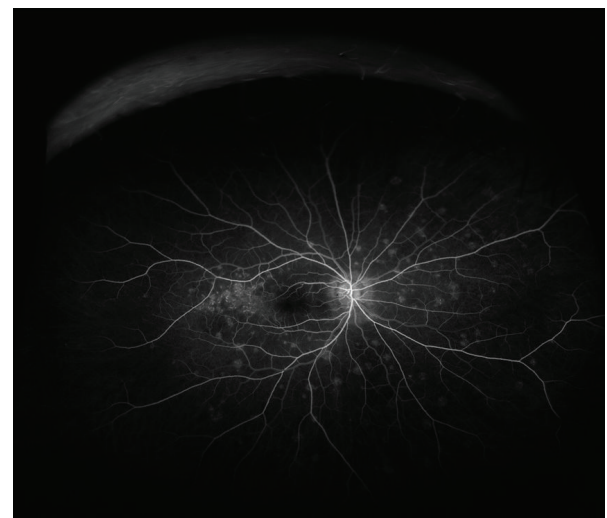

(b)

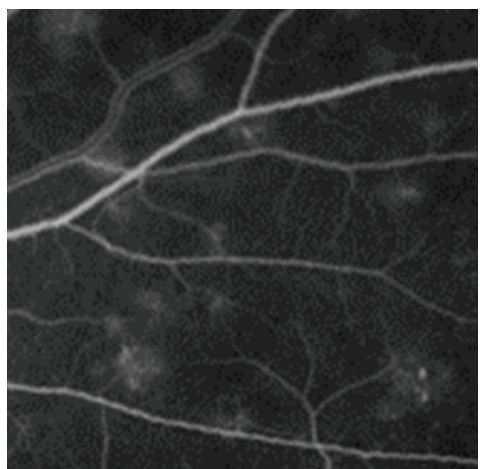

(d)

FIGURE 3: (a) Fundus photograph and corresponding (b) fluorescein angiogram (FA) demonstrating classic wreath-like patterns in MEWDS. (c) Fundus photograph of the macula of different patient demonstration foveal granularity and (d) magnified view of the wreath-like patterns seen on FA in MEWDS.

When all patients from these articles were considered $(n=$ $77), 57$ patients (74\%) were female. The mean of the average age was 28.7 years old, with a range from 28-29.9 years old.

3.4. MFC. MFC, unlike classic APMPPE and MEWDS, is more likely to have irreversible visual damage and impairment (Figure 4). This syndrome simulates presumed ocular histoplasmosis (POHS) except that patients present with vitreous cells and inflammation. The punched-out chorioretinal scars with pigmented borders found in the posterior pole and periphery are similar to those in POHS. There is frequent development of choroidal neovascular membranes, which can cause severe vision loss [33]. This disease is usually bilateral with a predilection for patients in their third decade. Though the cause is unknown, it has been hypothesized that an exogenous pathogen may sensitize the individual, with subsequent episodes not requiring the inciting antigen. MFC tends to be a chronic disorder with, generally, a poorer visual prognosis. Some patients require systemic immunosuppression, while other treatments, such as photodynamic therapy and antivascular endothelial growth factor, are used to treat the resultant CNVM [34-36].

In evaluating the current literature for this review for MFC, data was obtained from 22 articles (Table 4) [3335, 37-56]. In PubMed, the term "multifocal choroiditis and panuveitis," using all or part of the term, brought up 184 articles. After reviewing and eliminating reports with less than 10 patients, no specificity on patient data for gender and age, and those reports in which data was repeated, 22 articles remained. All reports revealed female predominance, ranging from 55 to $100 \%$. When all patients from these articles were considered $(n=538), 406$ patients $(75 \%)$ were female. The mean of the average age was 39.2 years old, with a range from 30.2 to 57 years old. 
TABLE 3: Reports for multiple evanescent white dot syndrome.

\begin{tabular}{lcccc}
\hline Author & Year & No. of patients & No. of women (\%) & average Age (years) \\
\hline Asano et al. [31] & 2004 & 50 & $39(78)$ & 29.9 \\
Reddy et al. [32] & 1996 & 16 & $8(50)$ & 28.1 \\
Jampol et al. [29] & 1984 & 11 & $10(91)$ & 28 \\
\hline
\end{tabular}

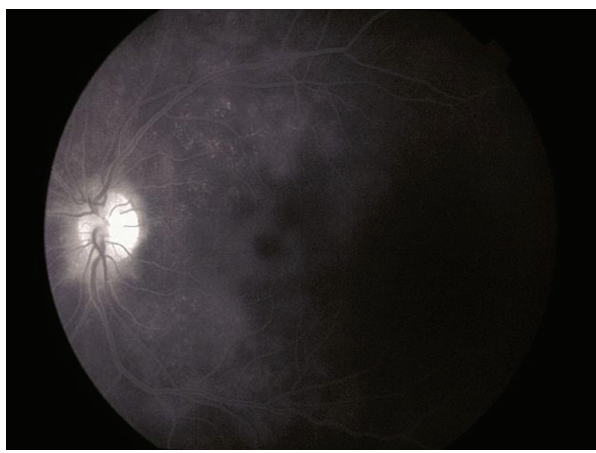

(a)

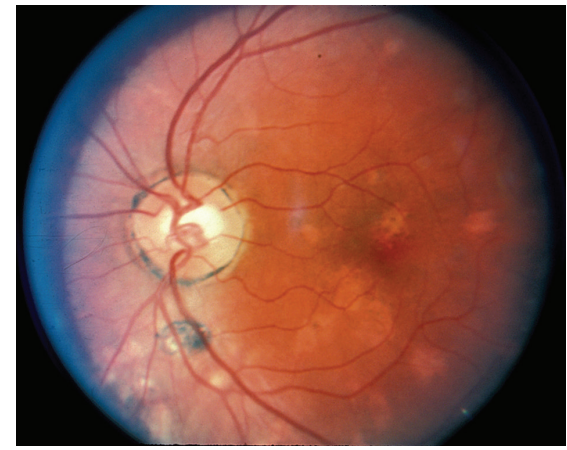

(b)

FIGURE 4: (a) Fluorescein angiogram of a patient with MFC demonstrating concurrent macular edema. (b) Fundus photograph of a patient with MFC requiring systemic immunosuppression.

3.5. PIC. PIC, a possible variant of MFC, was first described by Watzke et al [57]. This disease was originally described in young, myopic women with punched-out lesions of the posterior pole without ocular inflammation. Like MFC, CNVM may develop and contribute to vision loss (Figure 5).

In evaluating the current literature for PIC, data was obtained from 13 articles (Table 5) [33, 57-64]. In PubMed, the term "punctate inner choroidopathy," using all or parts of the term, brought up 76 articles. After reviewing and eliminating reports with less than 10 patients, no specificity on patient data for gender and age, and those in which data was repeated, 13 articles remained. All 13 articles revealed female predominance, ranging from 64 to $100 \%$. When all patients from these articles were considered $(n=471), 400$ patients $(85 \%)$ were female. The mean of the average age was 33.1 years old, with a range from 26 to 41.5 years old.

3.6. AZOOR. AZOOR, thought of predominantly in young women, includes a rapid loss of one or more large zones of outer retinal function and photopsias with minimal fundus changes. Though the cause is unknown, $28 \%$ of patients had associated autoimmune diseases, such as Hasimoto's thyroiditis and relapsing transverse myelopathy [65]. No treatment has found to be effective. In Gass' series, $78 \%$ of patients with AZOOR had stabilization of the visual field loss and $20 \%$ had improvement [65].

In evaluating the current literature for AZOOR, data was obtained from 5 articles (Table 6) [66-70]. In PubMed, the term "acute zonal occult outer retinopathy," using all or part of the term, brought up 82 articles. After reviewing and eliminating reports with less than 10 patients, no specificity on patient data for gender and age, and those with repeated data, 5 articles remained. All articles revealed female predominance, ranging from 75 to $93 \%$. When all patients from these articles were considered ( $n=190), 150$ patients $(79 \%)$ were female. The mean of the average age was 38 years old, with a range from 33 to 49.1 years old.

3.7. Summary of Gender Differences in Prevalence. A summary of the gathered data from this paper is provided in Table 7. A review of the presented data appears to demonstrate female predominance, in order from most to least, in the following diseases: $\mathrm{PIC}>\mathrm{AZOOR}>\mathrm{MFC}>\mathrm{MEWDS}$. There appeared to be very slight female predominance in BCR in this review. Very slight male predominance was seen in APMPPE in this review. As for age at onset, from youngest to oldest, this review revealed APMPPE $>$ MEWDS $>$ PIC > AZOOR $>$ MFC $>$ BCR. The BCR patients, on average, were twice as old as the patients of the other WDS for age of onset.

3.8. Gender Differences in Clinical Presentations. Though some of the above white dot syndromes have differences in the ratios of involvement of men to women, no clinical differences have been described between the sexes [1-3, 5, 8-15, 17$20,24,26-29,31-33,37,38,44-47,50-52,54-59,61,62,65$, 68-71]. In review of the reports, no distinctions were made between the genders in age of onset, initial clinical findings, or severity of disease.

3.9. Gender Differences in Treatment and Prognosis. Though this review revealed female predominance in PIC, AZOOR, MFC, and MEWDS, treatment differences have not been documented between these and the other white dot syndromes $[34,35,48,61]$. This should be considered in future studies as differences in response to steroids in SLE, another female predominant autoimmune disease $(9: 1)$, have been noted [72]. Estrogens have been implicated as enhancers of the immune 
TABLE 4: Reports for multifocal choroiditis and panuveitis.

\begin{tabular}{|c|c|c|c|c|}
\hline Author & Year & No. of patients & No. of women (\%) & average Age (years) \\
\hline Fung et al. [37] & 2013 & 41 & $29(70.7)$ & 38.4 \\
\hline Spaide et al. [38] & 2013 & 17 & $13(78.3)$ & 33 \\
\hline Parodi et al. [39] & 2013 & 14 & $9(64)$ & 48 \\
\hline Mansour et al. [40] & 2012 & 12 & $9(75)$ & 37.8 \\
\hline Atan et al. [41] & 2011 & 30 & $20(67)$ & 57 \\
\hline Parodi et al. [42] & 2010 & 27 & $18(67)$ & 39 \\
\hline Kotsolis et al. [43] & 2010 & 17 & $14(82)$ & 42.7 \\
\hline Haen and Spaide [44] & 2008 & 18 & $15(83)$ & 43.2 \\
\hline Kedhar et al. [45] & 2007 & 66 & $50(75.8)$ & 49 \\
\hline Thorne et al. [46] & 2006 & 66 & $50(76)$ & 45 \\
\hline MacLaren and Lightman [47] & 2006 & 20 & $11(55)$ & 37.1 \\
\hline Vianna et al. [48] & 2006 & 19 & $13(68)$ & 46.2 \\
\hline Parodi et al. [49] & 2004 & 13 & $11(85)$ & 47 \\
\hline Michel et al. [34] & 2002 & 19 & $15(79)$ & 34.8 \\
\hline Spaide et al. [35] & 2002 & 17 & $15(88)$ & 34.2 \\
\hline Parnell et al. [50] & 2001 & 25 & $23(92)$ & 31.1 \\
\hline Vadalà et al. [51] & 2001 & 13 & $13(100)$ & 33 \\
\hline Slakter et al. [52] & 1997 & 14 & $8(57)$ & 31 \\
\hline Brown Jr. et al. [33] & 1996 & 41 & $32(78)$ & 36 \\
\hline Tiedeman [53] & 1987 & 10 & $6(60)$ & 36.6 \\
\hline Morgan and Schatz [54] & 1986 & 11 & $11(100)$ & 30.2 \\
\hline Dreyer and Gass [55] & 1984 & 28 & $21(75)$ & 33 \\
\hline${ }^{*}$ Watzke and Claussen [56] & 1981 & 40 & N/A & $\mathrm{N} / \mathrm{A}$ \\
\hline
\end{tabular}

${ }^{*}$ Not included in data analysis.

TABLE 5: Reports for punctate inner choroidopathy.

\begin{tabular}{|c|c|c|c|c|}
\hline Author & Year published & No. of patients & No. of women (\%) & average Age (years) \\
\hline Zhang et al. [58] & 2013 & 42 & $27(64)$ & 26 \\
\hline Spaide et al. [38] & 2013 & 13 & $12(92)$ & 38 \\
\hline Mansour et al. [40] & 2012 & 24 & $19(79)$ & 41.5 \\
\hline Zhang et al. [60] & 2012 & 12 & $11(92)$ & 32.9 \\
\hline Zhang et al. [59] & 2011 & 75 & $54(72)$ & 32 \\
\hline Patel et al. [61] & 2011 & 12 & $11(92)$ & 32 \\
\hline Atan et al. [41] & 2011 & 31 & $26(84)$ & 40 \\
\hline Essex et al. [62] & 2010 & 136 & $126(93)$ & 32 \\
\hline Menezo et al. [63] & 2010 & 10 & $8(80)$ & 40.7 \\
\hline Kedhar et al. [45] & 2007 & 13 & $12(92)$ & 29 \\
\hline Gerstenblith et al. [64] & 2007 & 77 & $69(90)$ & 30 \\
\hline Brown Jr. et al. [33] & 1996 & 16 & $15(94)$ & 30 \\
\hline Watzke et al. [57] & 1984 & 10 & $10(100)$ & 26.8 \\
\hline
\end{tabular}

TABLE 6: Reports for acute zonal occult outer retinopathy.

\begin{tabular}{lcccc}
\hline Author & Year published & No. of patients & No. of women (\%) & average Age (years) \\
\hline Jiang et al. [66] & 2013 & 14 & $13(93)$ & 33 \\
Saito et al. [67] & 2013 & 11 & $10(91)$ & 35 \\
Monson and Smith [68] & 2011 & 130 & $99(76)$ & 36.7 \\
Fujiwara et al. [69] & 2010 & 11 & $10(91)$ & 49.1 \\
Jacobson et al. [70] & 1995 & 24 & $18(75)$ & 35 \\
\hline
\end{tabular}




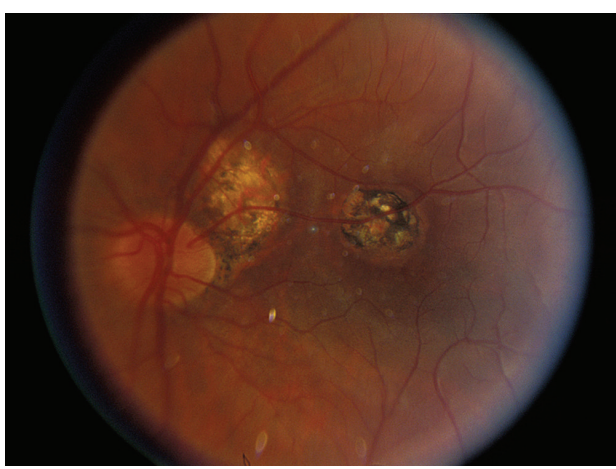

(a)

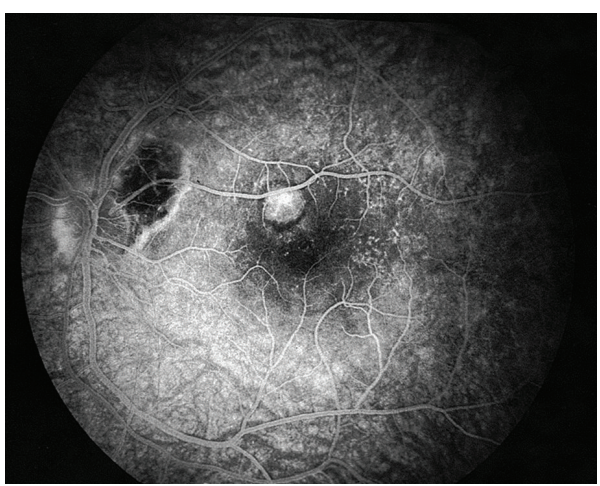

(c)

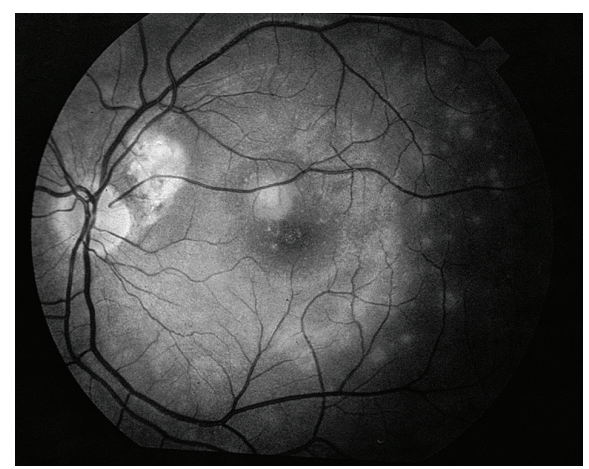

(b)

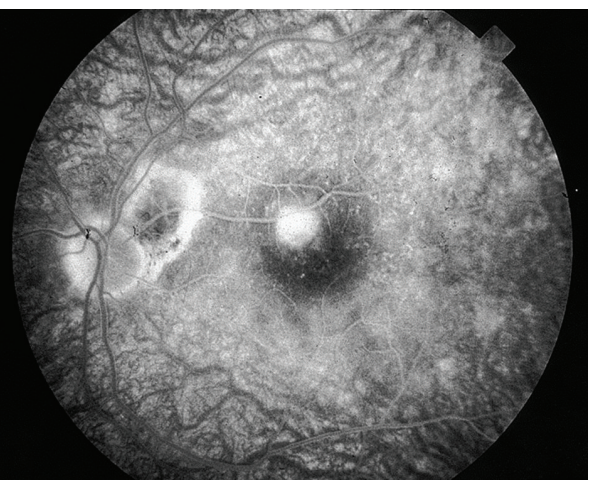

(d)

Figure 5: (a) Fundus photography and corresponding fluorescein angiogram ((b)-(d)) of a young woman with PIC demonstrating leakage consistent with a choroidal neovascular membrane.

TABLE 7: Summary of gathered data.

\begin{tabular}{lcc}
\hline Disease & Average age (years) & Gender analysis (\% women) \\
\hline BCR & 53.5 & $\mathrm{~F}>\mathrm{M}(58 \%)$ \\
APMPPE & 27.1 & $\mathrm{M}>\mathrm{F}(46 \%)$ \\
MEWDS & 28.7 & $\mathrm{~F}>\mathrm{M}(74 \%)$ \\
MFC & 39.2 & $\mathrm{~F}>\mathrm{M}(75 \%)$ \\
PIC & 33.1 & $\mathrm{~F}>\mathrm{M}(85 \%)$ \\
AZOOR & 38 & $\mathrm{~F}>\mathrm{M}(79 \%)$ \\
\hline
\end{tabular}

BCR: birdshot chorioretinopathy, APMPPE: acute posterior multifocal placoid pigment epitheliopathy, MEWDS: multiple evanescent white dot syndrome, MFC: multifocal choroiditis and panuveitis, PIC: punctate inner choroidopathy, AZOOR: acute zonal occult outer retinopathy.

system (with androgens and progesterone being considered immunosuppressors), and such possible explanations have been given for the differences in steroid response in SLE [72]. The other WDS diseases, without preference or with male predominance, also have not had treatment differences noted in the literature $[5,7,21-23,71,73,74]$. BCR, MFC, and PIC in general have poorer VA prognoses than APMPPE and MEWDS, though systemic immunomodulatory therapy may help to decrease the amount of vision loss in BCR, MFC, and PIC. MFC and MEWDS appear to be female dominant and on the different ends of the spectrum for disease prognosis, suggesting that gender, for these diseases, may have little to no effect on visual prognosis. The most abundant amount of data in the literature on treatment of the white dot syndrome diseases concerns BCR. Articles on the use of intravitreal triamcinolone, intravenous immunoglobulin, cyclosporine alone, cyclosporine plus mycophenolate mofetil, methotrexate, infliximab, and daclizumab can be found in the literature on the treatment of BCR with varying success and no mention of response differences between the genders $[5,7,21-23,71$, $73,74]$.

3.10. A Hormonal Difference? Sex hormones influence the immune system, resulting in females having higher immunoglobulin levels and mounting stronger immune responses following immunizations or infections than males [75]. However, this also increases woman's susceptibility to autoimmune diseases [75]. Abnormal hormone levels may trigger disease [75]. BCR tends to involve older patients, including women who may be menopausal. This is less likely to occur in the other WDS diseases, as they tend to be younger. This may be a possible reason why the ratio is much closer in female : male involvement in BCR than such diseases as PIC, AZOOR, MFC, and MEWDS. Unfortunately, this does not explain the near equal development of APMPPE in males and females, as the patients tend to be younger and this disease usually follows a viral prodrome. Clearly, there is something more. Other factors, such as the involvement of HLA A29 factor in BCR, may influence the occurrence of disease [71]. 


\section{Conclusion}

In conclusion, though in this review PIC, AZOOR, MFC, and MEWD were found to have female predominance, there does not appear to be a significant difference in clinical presentation nor in the treatment of these diseases between the genders. BCR and APMPPE appear to affect both men and women equally and again, both in presentation and treatment, there does not appear to be a significant difference between the genders. Though estrogens have been implicated in the manipulations of the immune system, further work is needed to truly elicit how estrogen levels may affect prevalence, presentation, and treatment in these ocular diseases.

\section{Conflict of Interests}

The author declares that there is no conflict of interests regarding the publication of this paper.

\section{References}

[1] A. Franceschaetti and J. Babel, "La choriorétinite en täche de bougie, manifestation de la maladie de Besnier-Boeck," Ophthalmologica, vol. 118, pp. 701-710, 1949.

[2] S. J. Ryan and A. E. Maumenee, "Birdshot retinochoroidopathy," American Journal of Ophthalmology, vol. 89, no. 1, pp. 31-45, 1980.

[3] D. E. Henderly, A. J. Genstler, R. E. Smith, and N. A. Rao, "Changing patterns of uveitis," American Journal of Ophthalmology, vol. 103, no. 2, pp. 131-136, 1987.

[4] A. Rodriguez, M. Calonge, M. Pedroza-Seres et al., "Referral patterns of uveitis in a tertiary eye care center," Archives of Ophthalmology, vol. 114, no. 5, pp. 593-599, 1996.

[5] A. T. Gasch, J. A. Smith, and S. M. Whitcup, "Birdshot retinochoroidopathy," British Journal of Ophthalmology, vol. 83, no. 2, pp. 241-249, 1999.

[6] K. H. Shah, R. D. Levinson, F. Yu et al., "Birdshot chorioretinopathy," Survey of Ophthalmology, vol. 50, no. 6, pp. 519541, 2005.

[7] S. Kiss, M. Ahmed, E. Letko, and C. S. Foster, "Long-term follow-up of patients with birdshot retinochoroidopathy treated with corticosteroid-sparing systemic immunomodulatory therapy," Ophthalmology, vol. 112, no. 6, pp. 1066-1071, 2005.

[8] A. Rothova, T. T. J. M. Berendschot, K. Probst, B. Van Kooij, and G. S. Baarsma, "Birdshot chorioretinopathy: long-term manifestations and visual prognosis," Ophthalmology, vol. 111, no. 5, pp. 954-959, 2004.

[9] J. E. Thorne, D. A. Jabs, S. R. Kedhar, G. B. Peters, and J. P. Dunn, "Loss of visual field among patients with birdshot chorioretinopathy," American Journal of Ophthalmology, vol. 145, no. 1, pp. 23-28, 2008.

[10] J. E. Thorne, D. A. Jabs, G. B. Peters, D. Hair, J. P. Dunn, and J. H. Kempen, "Birdshot retinochoroidopathy: ocular complications and visual impairment," American Journal of Ophthalmology, vol. 140, no. 1, pp. 45.e1-45.e7, 2005.

[11] P. A. Keane, M. Allie, S. J. Turner et al., "Characterization of birdshot chorioretinopathy using extramacular enhanced depth optical coherence tomography," JAMA Ophthalmology, vol. 131, no. 3, pp. 341-350, 2013.

[12] P. Yang and C. S. Foster, "Interleukin 21, interleukin 23, and transforming growth factor $\beta 1$ in HLA-A29-associated birdshot retinochoroidopathy,' American Journal of Ophthalmology, vol. 156, no. 2, pp. 400-406, 2013.

[13] M. Papadia and C. P. Herbort, "Reappraisal of birdshot retinochoroiditis (BRC): a global approach," Graefe's Archive for Clinical and Experimental Ophthalmology, vol. 251, no. 3, pp. 861869, 2013.

[14] J. J. W. Kuiper, T. Mutis, W. De Jager, J. D. F. De GrootMijnes, and A. Rothova, "Intraocular interleukin-17 and proinflammatory cytokines in HLA-A-29-associated birdshot chorioretinopathy," American Journal of Ophthalmology, vol. 152, no. 2, pp. 177-182, 2011.

[15] G. P. Giuliari, S. Pujari, M. Shaikh, D. Marvell, and C. S. Foster, "Microperimetry findings in patients with birdshot chorioretinopathy," Canadian Journal of Ophthalmology, vol. 45, no. 4, pp. 399-403, 2010.

[16] C. Pagnoux, A. Mahr, A. Aouba et al., "Extraocular manifestations of birdshot chorioretinopathy in 118 French patients," Presse Medicale, vol. 39, no. 5, pp. e97-e102, 2010.

[17] L. Trinh, B. Bodaghi, C. Fardeau et al., "Clinical features, treatment methods, and evolution of birdshot chorioretinopathy in 5 different families," American Journal of Ophthalmology, vol. 147, no. 6, pp. 1042-1047, 2009.

[18] P. J. Kappel, D. Monnet, F. Yu, A. P. Brezin, R. D. Levinson, and G. N. Holland, "Contrast sensitivity among patients with birdshot chorioretinopathy," American Journal of Ophthalmology, vol. 147, no. 2, pp. 351-356, 2009.

[19] D. Monnet, A. P. Brézin, G. N. Holland et al., "Longitudinal cohort study of patients with birdshot chorioretinopathy. I. Baseline clinical characteristics," American Journal of Ophthalmology, vol. 141, no. 1, pp. 135-142, 2006.

[20] L. Sobrin, B. L. Lam, M. Liu, W. J. Feuer, and J. L. Davis, "Electroretinographic monitoring in birdshot chorioretinopathy," American Journal of Ophthalmology, vol. 140, no. 1, pp. 52-64, 2005.

[21] A. Rothova, A. Ossewaarde-Van Norel, L. I. Los, and T. T. J. M. Berendschot, "Efficacy of low-dose methotrexate treatment in birdshot chorioretinopathy," Retina, vol. 31, no. 6, pp. 1150-1155, 2011.

[22] P. Artornsombudh, O. Gevorgyan, A. Payal, S. Siddique, and C. S. Foster, "Infliximab treatment of patients with birdshot retinochoroidopathy," Ophthalmology, vol. 120, pp. 588-592, 2013.

[23] R. A. Cervantes-Castaneda, L. A. Gonzalez-Gonzalez, and M. Cordero-Coma, "Combined therapy of cyclosporine A and mycophenolate mofetil for the treatment of birdshot retinochoroidopathy: a 12-month follow-up," British Journal of Ophthalmology, vol. 97, pp. 637-643, 2013.

[24] J. D. Gass, "Acute posterior multifocal placoid pigment epitheliopathy," Archives of Ophthalmology, vol. 80, no. 2, pp. 177-185, 1968.

[25] D. A. Quillen, J. B. Davis, J. L. Gottlieb et al., “The white dot syndromes," American Journal of Ophthalmology, vol. 137, no. 3, pp. 538-550, 2004.

[26] B. C. Thomas, C. Jacobi, M. Korporal, M. D. Becker, B. Wildemann, and F. Mackensen, "Ocular outcome and frequency of neurological manifestations in patients with acute posterior multifocal placoid pigment epitheliopathy (APMPPE)," Journal of Ophthalmic Inflammation and Infection, vol. 2, no. 3, pp. 125131, 2012.

[27] T. Fiore, B. Iaccheri, S. Androudi et al., "Acute posterior multifocal placoid pigment epitheliopathy: outcome and visual prognosis," Retina, vol. 29, no. 7, pp. 994-1001, 2009. 
[28] N. P. Jones, "Acute posterior multifocal placoid pigment epitheliopathy," British Journal of Ophthalmology, vol. 79, no. 4, pp. 384-389, 1995.

[29] L. M. Jampol, P. A. Sieving, and D. Pugh, "Multiple evanescent white dot syndrome. I. Clinical findings," Archives of Ophthalmology, vol. 102, no. 5, pp. 671-674, 1984.

[30] T. M. Aaberg, R. V. Campo, and L. Joffe, "Recurrences and bilaterality in the multiple evanescent white-dot syndrome," American Journal of Ophthalmology, vol. 100, no. 1, pp. 29-37, 1985.

[31] T. Asano, M. Kondo, N. Kondo, S. Ueno, H. Terasaki, and Y. Miyake, "High prevalence of myopia in Japanese patients with multiple evanescent white dot syndrome," Japanese Journal of Ophthalmology, vol. 48, no. 5, pp. 486-489, 2004.

[32] C. V. Reddy, J. Brown Jr., J. C. Folk et al., "Enlarged blind spots in chorioretinal inflammatory disorders," Ophthalmology, vol. 103, no. 4, pp. 606-617, 1996.

[33] J. Brown Jr., J. C. Folk, C. V. Reddy, and A. E. Kimura, "Visual prognosis of multifocal choroiditis, punctate inner choroidopathy, and the diffuse subretinal fibrosis syndrome," Ophthalmology, vol. 103, no. 7, pp. 1100-1105, 1996.

[34] S. S. Michel, A. Ekong, S. Baltatzis, and C. S. Foster, "Multifocal choroiditis and panuveitis: Immunomodulatory therapy," Ophthalmology, vol. 109, no. 2, pp. 378-383, 2002.

[35] R. F. Spaide, K. B. Freund, J. Slakter, J. Sorenson, L. A. Yannuzzi, and Y. Fisher, "Treatment of subfoveal choroidal neovascularization associated with multifocal choroiditis and panuveitis with photodynamic therapy," Retina, vol. 22, no. 5, pp. 545-549, 2002.

[36] D. A. Cionni, S. A. Lewis, M. R. Petersen et al., "Analysis of outcomes for intravitreal bevacizumab in the treatment of choroidal neovascularization secondary to ocular histoplasmosis," Ophthalmology, vol. 119, no. 2, pp. 327-332, 2012.

[37] A. T. Fung, S. Pal, N. A. Yannuzzi et al., "MULTIFOCAL CHOROIDITIS WITHOUT PANUVEITIS: clinical characteristics and progression," Retina, vol. 34, no. 1, pp. 98-107, 2014.

[38] R. F. Spaide, N. Goldberg, and K. B. Freund, "Redefining multifocal choroiditis and panuveitis and punctate inner choroidopathy through multimodal imaging," Retina, vol. 33, no. 7, pp. 1315-1324, 2013.

[39] M. B. Parodi, P. Iacono, A. Mansour et al., "Intravitreal bevacizumab for juxtafoveal choroidal neovascularization secondary to multifocal choroiditis," Retina, vol. 33, no. 5, pp. 953956, 2013.

[40] A. M. Mansour, J. F. Arevalo, C. Fardeau et al., "Three-year visual and anatomic results of administrating intravitreal bevacizumab in inflammatory ocular neovascularization," Canadian Journal of Ophthalmology, vol. 47, no. 3, pp. 269-274, 2012.

[41] D. Atan, S. Fraser-Bell, J. Plskova et al., "Punctate inner choroidopathy and multifocal choroiditis with panuveitis share haplotypic associations with IL10 and TNF loci," Investigative Ophthalmology \& Visual Science, vol. 52, no. 6, pp. 3573-3581, 2011.

[42] M. B. Parodi, P. Iacono, D. S. Kontadakis, I. Zucchiatti, M. L. Cascavilla, and F. Bandello, "Bevacizumab vs photodynamic therapy for choroidal neovascularization in multifocal choroiditis," Archives of Ophthalmology, vol. 128, no. 9, pp. 1100$1103,2010$.

[43] A. I. Kotsolis, F. A. Killian, I. D. Ladas, and L. A. Yannuzzi, "Fluorescein angiography and optical coherence tomography concordance for choroidal neovascularisation in multifocal choroidtis," British Journal of Ophthalmology, vol. 94, no. 11, pp. 1506-1508, 2010.
[44] S. P. Haen and R. F. Spaide, "Fundus autofluorescence in multifocal choroiditis and panuveitis," American Journal of Ophthalmology, vol. 145, no. 5, pp. 847-853, 2008.

[45] S. R. Kedhar, J. E. Thorne, S. Wittenberg, J. P. Dunn, and D. A. Jabs, "Multifocal choroiditis with panuveitis and punctate inner choroidopathy: comparison of clinical characteristics at presentation," Retina, vol. 27, no. 9, pp. 1174-1179, 2007.

[46] J. E. Thorne, S. Wittenberg, D. A. Jabs et al., "Multifocal choroiditis with panuveitis. Incidence of ocular complications and of loss of visual acuity," Ophthalmology, vol. 113, no. 12, pp. 23102316, 2006.

[47] R. E. MacLaren and S. L. Lightman, "Variable phenotypes in patients diagnosed with idiopathic multifocal choroiditis," Clinical and Experimental Ophthalmology, vol. 34, no. 3, pp. 233238, 2006.

[48] R. N. G. Vianna, P. C. Özdal, J. Deschênes, and M. N. Burnier Jr., "Combination of azathioprine and corticosteroids in the treatment of serpiginous choroiditis," Canadian Journal of Ophthalmology, vol. 41, no. 2, pp. 183-189, 2006.

[49] M. B. Parodi, L. Di Crecchio, P. Lanzetta, A. Polito, F. Bandello, and G. Ravalico, "Photodynamic therapy with verteporfin for subfoveal choroidal neovascularization associated with multifocal choroiditis," American Journal of Ophthalmology, vol. 138, no. 2, pp. 263-269, 2004.

[50] J. R. Parnell, L. M. Jampol, L. A. Yannuzzi, J. D. M. Gass, and M. K. Tittl, "Differentiation between presumed ocular histoplasmosis syndrome and multifocal choroiditis with panuveitis based on morphology of photographed fundus lesions and fluorescein angiography," Archives of Ophthalmology, vol. 119, no. 2, pp. 208-212, 2001.

[51] M. Vadalà, G. Lodato, and S. Cillino, "Multifocal choroiditis: indocyanine green angiographic features," Ophthalmologica, vol. 215, no. 1, pp. 16-21, 2001.

[52] J. S. Slakter, A. Giovannini, L. A. Yannuzzi et al., "Indocyanine green angiography of multifocal choroiditis," Ophthalmology, vol. 104, no. 11, pp. 1813-1819, 1997.

[53] J. S. Tiedeman, "Epstein-Barr viral antibodies in multifocal choroiditis and panuveitis," American Journal of Ophthalmology, vol. 103, no. 5, pp. 659-663, 1987.

[54] C. M. Morgan and H. Schatz, "Recurrent multifocal choroiditis," Ophthalmology, vol. 93, no. 9, pp. 1138-1147, 1986.

[55] R. F. Dreyer and J. D. M. Gass, "Multifocal choroiditis and panuveitis: a syndrome that mimics ocular histoplasmosis," Archives of Ophthalmology, vol. 102, no. 12, pp. 1776-1784, 1984.

[56] R. C. Watzke and R. W. Claussen, "The long-term course of multifocal choroiditis (presumed ocular histoplasmosis)," American Journal of Ophthalmology, vol. 91, no. 6, pp. 750-760, 1981.

[57] R. C. Watzke, A. J. Packer, and J. C. Folk, "Punctate inner choroidopathy," American Journal of Ophthalmology, vol. 98, no. 5, pp. 572-584, 1984.

[58] X. Zhang, C. Zuo, M. Li, H. Chen, S. Huang, and F. Wen, "Spectral-domain optical coherence tomographic findings at each stage of punctate inner choroidopathy," Ophthalmology, vol. 120, no. 12, pp. 2678-2683, 2013.

[59] X. Zhang, F. Wen, C. Zuo et al., "Clinical features of punctate inner choroidopathy in Chinese patients," Retina, vol. 31, no. 8, pp. 1680-1691, 2011.

[60] H. Zhang, Z.-L. Liu, P. Sun, and F. Gu, "Intravitreal bevacizumab as primary treatment of choroidal neovascularization secondary to punctate inner choroidopathy: results of a 1-year prospective trial," Retina, vol. 32, no. 6, pp. 1106-1113, 2012. 
[61] K. H. Patel, A. D. Birnbaum, H. H. Tessler, and D. A. Goldstein, "Presentation and outcome of patients with punctate inner choroidopathy at a tertiary referral center," Retina, vol. 31, no. 7, pp. 1387-1391, 2011.

[62] R. W. Essex, J. Wong, S. Fraser-Bell et al., "Punctate inner choroidopathy: clinical features and outcomes," Archives of Ophthalmology, vol. 128, no. 8, pp. 982-987, 2010.

[63] V. Menezo, F. Cuthbertson, and S. M. Downes, "Positive response to intravitreal ranibizumab in the treatment of choroidal neovascularization secondary to punctate inner choroidopathy," Retina, vol. 30, no. 9, pp. 1400-1404, 2010.

[64] A. T. Gerstenblith, J. E. Thorne, L. Sobrin et al., "Punctate inner choroidopathy: a survey analysis of 77 persons," Ophthalmology, vol. 114, no. 6, pp. 1201-1204, 2007.

[65] J. D. Gass, A. Agarwal, and I. U. Scott, "Acute zonal occult outer retinopathy: a long-term follow-up study," American Journal of Ophthalmology, vol. 134, no. 3, pp. 329-339, 2002.

[66] L. B. Jiang, C. Y. Shen, F. Chen, W. Y. Yan, T. Y. Lai, and N. L. Wang, "Clinical features of retinal diseases masquerading as retrobulbar optic neuritis," Chinese Medical Journal, vol. 126, no. 17, pp. 3301-3306, 2013.

[67] M. Saito, W. Saito, Y. Hashimoto et al., "Correlation between decreased choroidal blood flow velocity and the pathogenesis of acute zonal occult outer retinopathy," Clinical \& Experimental Ophthalmology, 2013.

[68] D. M. Monson and J. R. Smith, "Acute zonal occult outer retinopathy," Survey of Ophthalmology, vol. 56, no. 1, pp. 23-35, 2011.

[69] T. Fujiwara, Y. Imamura, V. J. Giovinazzo, and R. F. Spaide, "Fundus autofluorescence and optical coherence tomographic findings in acute zonal occult outer retinopathy," Retina, vol. 30, no. 8, pp. 1206-1216, 2010.

[70] S. G. Jacobson, D. S. Morales, X. K. Sun et al., "Pattern of retinal dysfunction in acute zonal occult outer retinopathy," Ophthalmology, vol. 102, no. 8, pp. 1187-1198, 1995.

[71] R. D. Levinson and C. R. Gonzales, "Birdshot retinochoroidopathy: immunopathogenesis, evaluation, and treatment," Ophthalmology Clinics of North America, vol. 15, no. 3, pp. 343-350, 2002.

[72] V. Rider and N. I. Abdou, "Gender differences in autoimmunity: molecular basis for estrogen effects in systemic lupus erythematosus," International Immunopharmacology, vol. 1, no. 6, pp. 1009-1024, 2001.

[73] A. Shah and M. Branley, "Use of intravitreal triamcinolone in the management of birdshot retinochoroidopathy associated with cystoid macular oedema: a case study over a three-year period," Clinical and Experimental Ophthalmology, vol. 33, no. 4, pp. 442-444, 2005.

[74] P. LeHoang, N. Cassoux, F. George, N. Kullmann, and M. D. Kazatchkine, "Intravenous immunoglobulin (IVIg) for the treatment of birdshot retinochoroidopathy," Ocular Immunology and Inflammation, vol. 8, no. 1, pp. 49-57, 2000.

[75] D. Verthelyi, "Sex hormones as immunomodulators in health and disease," International Immunopharmacology, vol. 1, no. 6, pp. 983-993, 2001. 


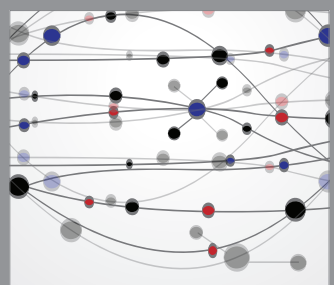

The Scientific World Journal
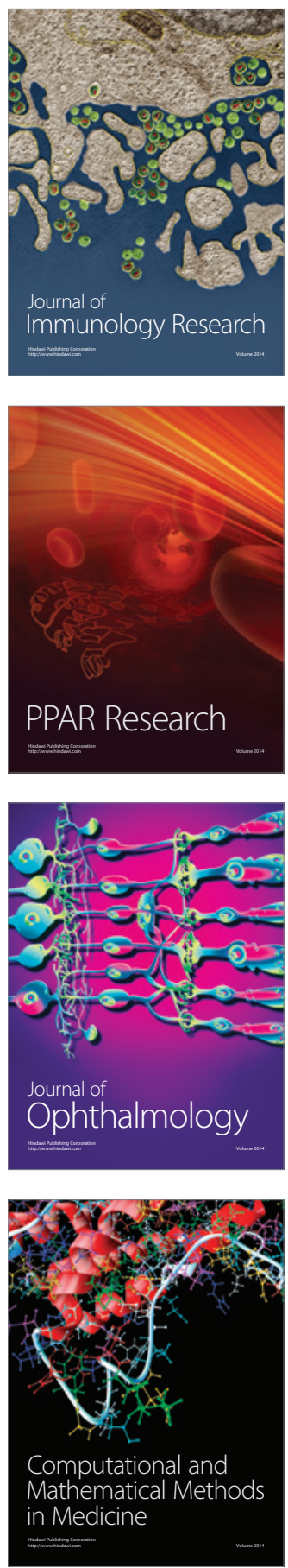

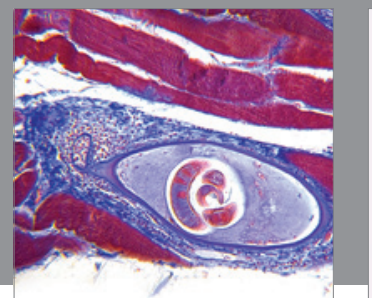

Gastroenterology

Research and Practice
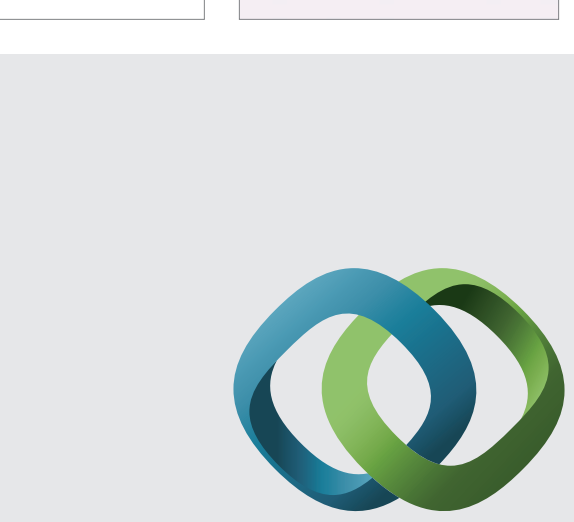

\section{Hindawi}

Submit your manuscripts at

http://www.hindawi.com
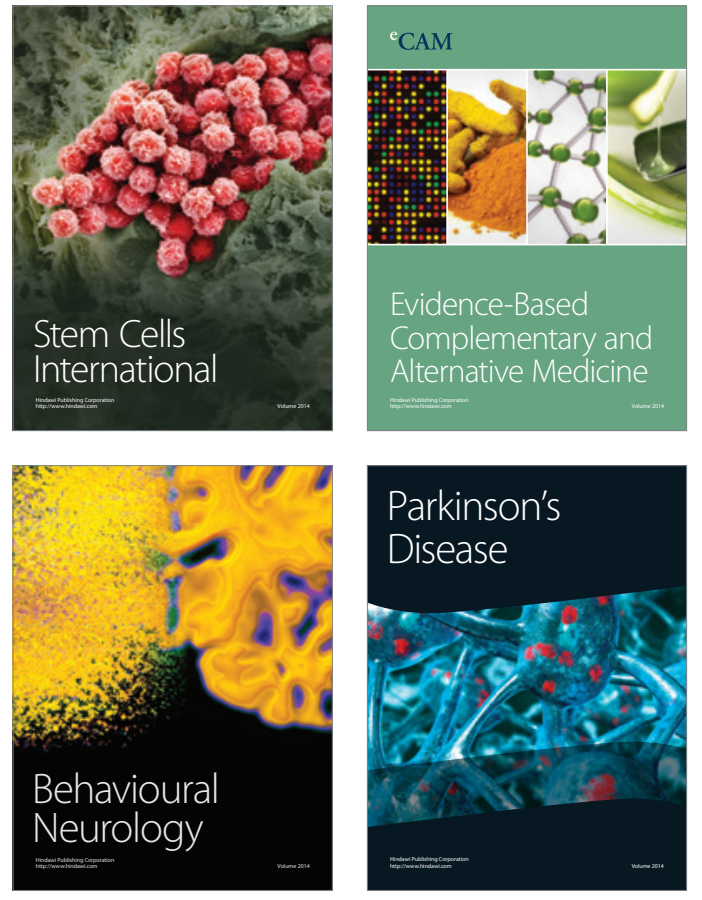
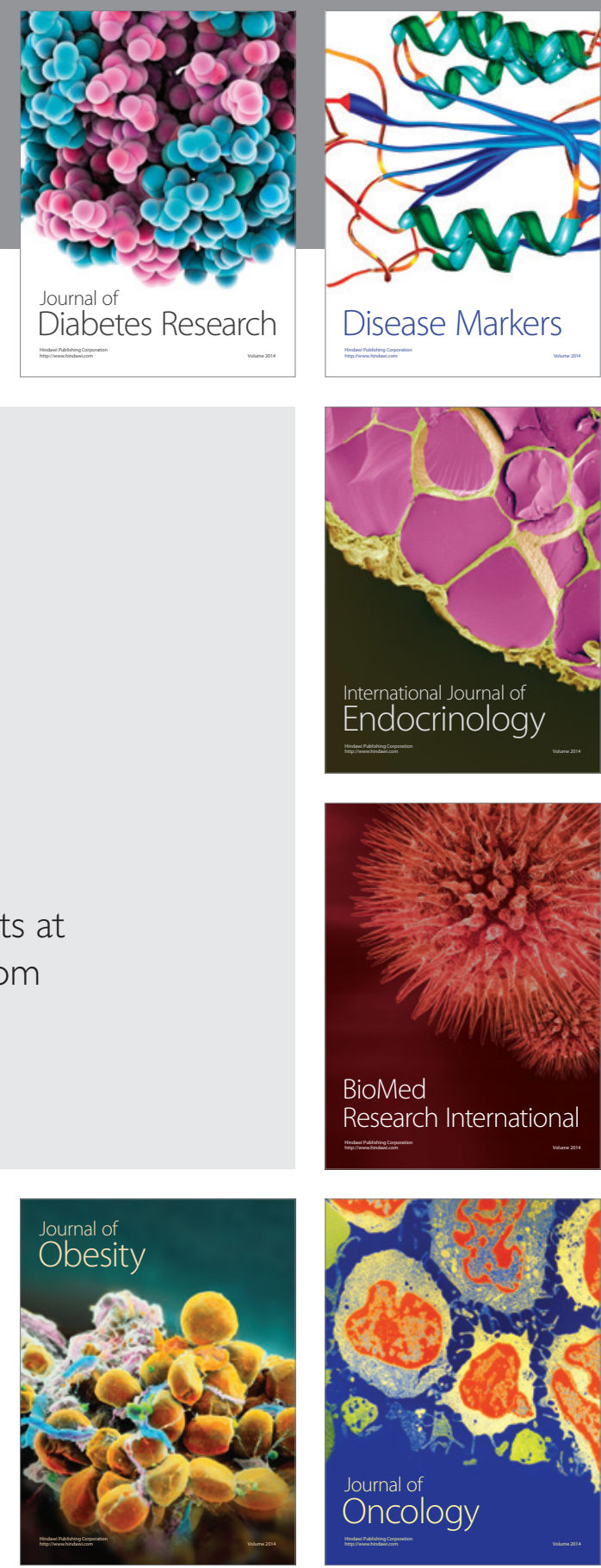

Disease Markers
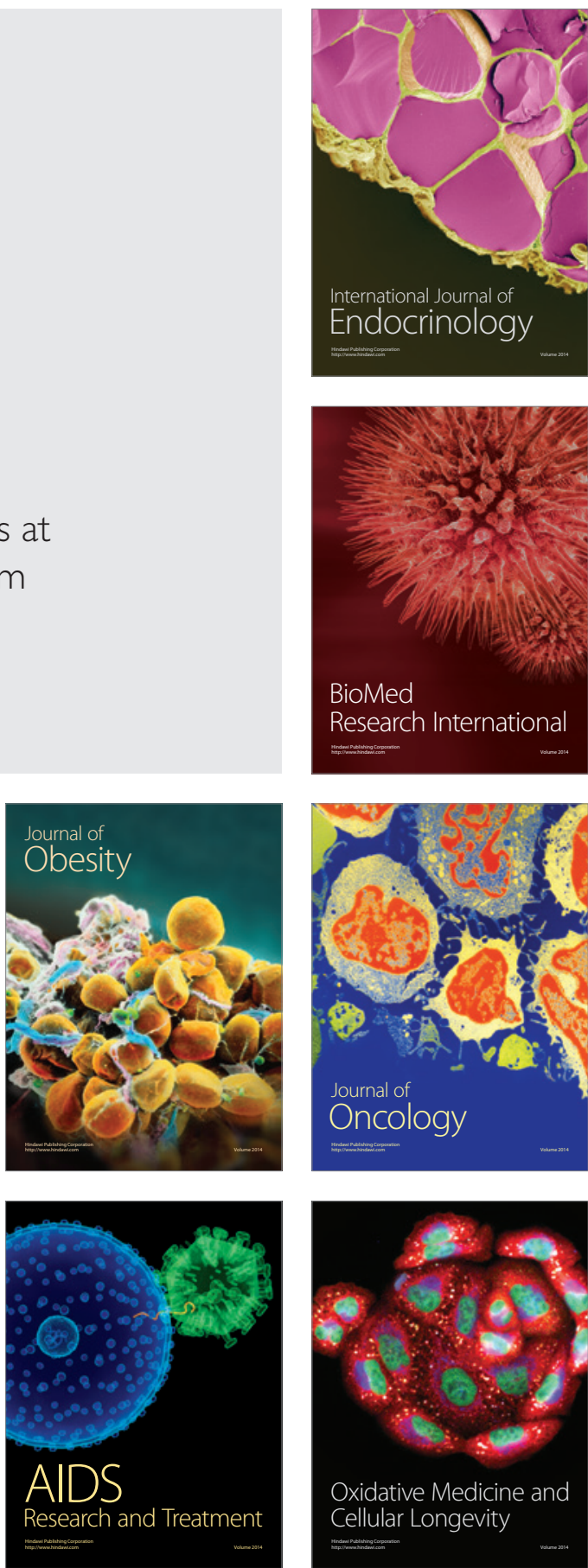